\title{
La antropología moral de la igualdad
}

\author{
ÁNGEL PUYOL GONZÁLEZ \\ Universidad Autónoma de Barcelona
}

\section{Introducción}

La igualdad es un principio fundamental de la filosofía política actual. Por una parte, los movimientos sociales y políticos de los siglos XIX y Xx han tenido su raíz más profunda en la idea de que los seres humanos somos iguales en aspectos fundamentales de la moralidad. Por otra parte, sin embargo, la igualdad nos ha mostrado a menudo, también en este tiempo, su cara más trágica: las tiranías políticas comunistas, la violación de las libertades individuales, la violencia que en ocasiones ha generado, la planificación ineficiente, una falsa camaradería. Sin embargo, y a pesar del miedo a la igualdad que aún perdura en buena parte del pensamiento contemporáneo ${ }^{2}$, todavía seguimos convencidos de que nuestras diferencias de aspecto, de talentos, de origen o de creencias no deberían enturbiar el mandato heredado de la razón ilustrada que nos dice que tanto yo como los demás poseemos las mismas necesidades básicas y los mismos derechos. Y que, por lo tanto, merecemos una igualdad de trato, tanto en un nivel jurídico y político (que ya la poseemos ${ }^{3}$ ), como en un nivel económico ${ }^{4}$, social ${ }^{5}$ e incluso en la vida privada ${ }^{6}$ (donde aún no es lo bastante satisfactoria).

Esa necesaria igualdad de trato tiene su referente ético y filosófico en la igualdad moral. La igualdad moral de las personas actúa de fundamento para el resto de las igualdades citadas. Sin embargo, a pesar de que nadie duda ya de que la igualdad moral supone una idea común de racionalidad y de capacidades morales en todos los individuos, creo que todavía se puede juzgar a las diferentes teorías políticas actuales, incluidas las teorías de la igualdad y de la justicia distributiva, en función de las diferencias en cuanto a la interpretación de la igualdad moral.

En este artículo, quiero analizar la idea de igualdad moral que subyace a las teorías liberales de la igualdad. Pienso que los igualitarismos liberales de autores como John Rawls, Ronald Dworkin y otros ${ }^{7}$ parten de una concepción inadecuada de la igualdad moral. Ello se debe al origen de sus teorías normativas. La teoría liberal de la igualdad nace como alternativa a las violaciones que el utilitarismo, la teoría ética normativa más destacada de mediados del siglo $\mathrm{xx}$, infringe a la idea de igualdad. Aunque el utilitarismo ha proporcionado una base teórica consistente para fundamentar la economía normativa del Estado de bienestar, también ha mostrado su incapacidad para integrar en un sistema coherente el conjunto de nuestras intuiciones morales básicas sobre la igualdad. Para recuperar el respeto por la igualdad moral, los igualitaristas liberales han resaltado el origen kantiano de la moralidad y su mandato de la dignidad humana: no hay que tratar a nadie solamente como un medio, sino siempre y a la vez como un fin en sí mismo.

Sin embargo, creo que la concepción moral de la persona de origen kantiano que proponen los igualitaristas liberales continúa siendo insuficiente para recoger nuestras intuiciones morales básicas acerca de la igualdad moral. Esa insuficiencia se muestra sobre todo en el terreno de la justicia distributiva.

Por esas razones, muestro, en primer lugar, la concepción moral de la persona que mantienen los utilitaristas. En segundo 
lugar, analizo el origen y las consecuencias de la concepción política de la persona que propone Rawls como oposición a la utilitarista. Finalmente, y después de un análisis crítico de las objeciones más importantes que la filosofía contemporánea ha lanzado contra la concepción rawlsiana de la persona, subrayo que la concepción kantiano-liberal de la persona debería ser sustituida por otra que incluyese a las necesidades y a las capacidades básicas de los individuos entre los atributos que una teoría de la igualdad debería tener en cuenta. De no ser así, no se producirá un equilibrio reflexivo completo entre nuestras intuiciones morales básicas acerca de la igualdad y los principios que la filosofía debe elaborar para recoger esas intuiciones en un sistema coherente.

\section{La antropología moral del utilitarismo}

El bienestar o utilidad es el criterio que usa el utilitarismo para juzgar el nivel de desigualdad entre las personas. La manera que tiene el Estado de saber si sus ciudadanos se encuentran bien o mal tratados, o de si debería intervenir para aplicar políticas de justicia distributiva, es atender al nivel de bienestar de las personas. Pero, a pesar de que el bienestar es un elemento muy presente en la vida de todos nosotros para valorar la situaciones personales, ha resultado ser un concepto esquivo para la filosofía. Por esa razón, la definición de bienestar o de utilidad ha variado con los distintos enfoques del utilitarismo. Placer, felicidad, satisfacción de estados mentales, satisfacción de preferencias, satisfacción de preferencias racionales, son diferentes versiones del bienestar, pero ninguna de ellas altera el propósito básico del utilitarismo de juzgar totalmente la bondad de una situación según la bondad de las utilidades de esa situación ${ }^{8}$.

En ese contexto, las personas se consideran, desde el punto de vista moral y distributivo, como depósitos de bienestar, como lugares que albergan las actividades del deseo y de la obtención del placer y del dolor. Más allá del bienestar o utilidad, el utilitarismo no está interesado en recoger nueva información moralmente relevante sobre la persona. La importancia moral de la persona se reduce así a la utilidad que es capaz de fabricar. La voluntad, los objetivos personales, las intenciones, la libertad de elección o los afectos no son atributos morales valiosos por sí mismos, sino por los efectos que tienen sobre la utilidad o el bienestar. Sin embargo, las críticas más enérgicas dirigidas al utilitarismo no han venido por la dificultad de clarificar un término que ha resultado tan impreciso, sino por su utilización como medida de la justicia distributiva. El fondo de la crítica es que el bienestar no sólo no recoge la información moral pertinente para juzgar las situaciones de desigualdad, sino que además puede convertirse él mismo en causante o encubridor de una mayor desigualdad. Rawls se ha erigido en uno de los mayores promotores de ese tipo de objeción.

Para el filósofo de Harvard, el utilitarismo concibe a la persona como un mero recipiente de experiencias. No importa quién posee las experiencias, ni cuál es su distribución secuencial entre las personas. Estas consideraciones son sólo cuestiones de espacio y de tiempo y, como tales, irrelevantes. Lo que es realmente valioso para el utilitarismo son las experiencias mismas. Y la tarea de la justicia debe ser la optimización de esas experiencias tomadas en su conjunto, sin importar quiénes son sus propietarios. Como consecuencia, el utilitarismo pasa por alto uno de los requisitos morales indispensables que debería poseer una teoría de la justicia: la individualidad ${ }^{9}$.

El utilitarismo viola la individualidad de la persona porque al utilizar la utilidad como la única información moral valiosa para realizar cálculos distributivos, independientemente de los detentores de esa 
utilidad, no distingue entre quiénes deben recibir la utilidad distribuida. En palabras del propio Rawls, «la característica más sorprendente de la visión utilitarista de la justicia es que no importa, excepto de manera indirecta, cómo se distribuye esta suma de satisfacciones entre los individuos; como tampoco importa, excepto de manera indirecta, cómo un hombre distribuye sus satisfacciones en el tiempo. La distribución correcta en cada caso es la que produce la máxima satisfacción» ${ }^{10}$.

La indiferencia del utilitarismo sobre la individualidad le conduce a reconocer una especie de fusión de muchas personas en sólo una o, como señala Rawls, a no tomarse seriamente la distinción entre las personas. Aunque en un primer momento se puede suponer que el utilitarismo respeta la individualidad si pensamos, por ejemplo, en la teoría política que considera a cada persona como portadora de un voto, y sólo de uno ${ }^{11}$, en realidad la teoría utilitarista no es individualista, ya que funde los deseos o el bienestar de las distintas personas en una sola experiencia que el distribuidor utilitarista imagina como la experiencia de todos los miembros de la sociedad. El resultado es la impersonalidad, la no separabilidad de los individuos y, como consecuencia, «no hay en principio razón por la cual las mayores ganancias de alguno no han de compensar las menores pérdidas de otros o, lo que es más importante, por la que la violación de la libertad de unos pocos no se pudiera considerar correcta por un mayor bien compartido por muchos» 12

La no separabilidad de las personas desemboca, siempre bajo la concepción rawlsiana, pero también en la mayor parte del debate contemporáneo sobre derecho y bienestar ${ }^{13}$, en la violación de los derechos individuales. La concepción utilitarista de la persona, al no contemplar la individualidad, se ve incapaz de reconocer los derechos y libertades que protegen al individuo de las exigencias abusivas de la colec- tividad. No habría más derechos, para el utilitarismo, que los derivados de la igualdad de utilidades o de bienestar. Sin embargo, ese tipo de igualdad no garantiza la unidad moral del individuo. No existe un individuo separado moralmente de otro en alguna característica exclusiva o diferenciadora. El valor moral del individuo estaría sujeto al valor del bienestar colectivo.

Dworkin ha expresado con claridad las consecuencias que la concepción utilitarista de la persona tendría sobre la igualdad moral y la justicia. Aparentemente, el utilitarismo se muestra a sí mismo defendiendo la igualdad, debido a su compromiso con la imparcialidad estricta ${ }^{14}$. Así, si asociamos el bienestar a la satisfacción de las preferencias personales, éstas competirían por igual en la práctica social. Pero, si analizamos la variedad y el origen de esas preferencias, cosa que no hace el utilitarismo, ese igualitarismo resulta engañoso. Según Dworkin, podemos distinguir las preferencias personales (el deseo de disfrutar de ciertos bienes u oportunidades para mí) de las externas (la preferencia por la asignación de ciertos bienes u oportunidades para otros). Por ejemplo, mi preferencia porque yo ingrese en la universidad es una preferencia personal. En cambio, mi preferencia porque los demás ingresen o no en la misma universidad a la que yo quiero ir es una preferencia externa. Si ignoramos esa distinción a la hora de maximizar nuestras preferencias, el resultado puede ser discriminatorio con los demás. Si se da el caso, por ejemplo, de que muchas personas coinciden en desear que los negros o las mujeres no deberían estudiar en las universidades reservadas a hombres blancos, esa preferencia podría imponerse colectivamente bajo la argumentación utilitarista, que se limita a maximizar las preferencias de los individuos sin importarle si éstas socavan los intereses de personas moralmente iguales. Por esa razón, si no existe un mecanismo público de prevención con- 
tra las preferencias externas, como, por ejemplo, unos derechos individuales anteriores a todo cálculo maximizador de preferencias, entonces no podemos tratar a los demás como iguales. La igualdad exige prevenirnos contra las discriminaciones basadas en prejuicios, y el utilitarismo, con su intención de respetar a las preferencias en vez de a las personas, fracasa en esa tarea.

En resumen, la concepción utilitarista de la persona no sólo no separa las unidades morales que representa cada individuo, sino que tampoco distingue el origen de las preferencias en el individuo. Con ambas indiferencias el utilitarismo muestra la incapacidad de su concepción moral de la persona para tratar con igualdad a todos los individuos.

Los teóricos utilitaristas han desarrollado varias líneas de defensa contra los ataques recibidos en este campo. Hart representa uno de los exponentes más claros de esa defensa. En su opinión, la argumentación de Dworkin está mal fundamentada. Hart admite que el resultado del procedimiento democrático basado en la regla de la mayoría puede resultar a veces moralmente injusto, si se da el caso de que una mayoría discrimina a una minoría con el peso electoral de unas preferencias basadas en prejuicios. Pero no cree que eso sea una consecuencia de la concepción utilitarista de la persona, sino antes bien de la desinformación de los miembros de la mayoría sobre el valor moral de los miembros de la minoría. El problema de la democracia no se deriva, según Hart, de los presupuestos del utilitarismo, sino simplemente de que el procedimiento de la regla de la mayoría no garantiza la justicia de los resultados. La razón de ese desajuste entre la democracia y la justicia se encuentra en que las preferencias de la mayoría pueden estar mal informadas y ser insensibles al argumento de la justicia. Así, «una mayoría de votantes teóricamente independientes puede consolidar sus prejuicios debido a una tozudez auto-ensordecedora y auto-perpetuadora que no permite tener oportunidades equitativas a una minoría despreciada para argumentar públicamente su caso. Esto es posible y de hecho en ocasiones ha sucedido» ${ }^{15}$.

Hart parece sugerir que si el resultado injusto de la democracia proviene de una mala formación de las preferencias, basadas en prejuicios, eso no invalida el argumento utilitarista de tener en cuenta por igual las preferencias de los individuos. Los que conocen la justicia deben intentar convencer a los portadores de prejuicios de que están en un error, pero no anular ni el procedimiento de la democracia ni la legitimidad política de su resultado, aunque ambos caminen en dirección contraria a lo que intentan defender los derechos individuales. En palabras del mismo Hart, «incrementa tus números y entonces tus puntos de vista podrán vencer».

No obstante, creo que Hart confunde la igualdad moral con la igualdad procedimental. Aunque el procedimiento democrático garantice una igualdad formal (todos los individuos disponen sólo de un voto y ningún punto de vista moral sobresale sobre los demás sin el consentimiento de la mayoría), de aquí no se deriva un respeto a la igualdad moral. Es cierto que la igualdad moral es un concepto excesivamente abstracto, pero eso no significa que sea compatible con cualesquiera de las interpretaciones que se le puedan dar. Diferentes teorías del bien interpretan de maneras diversas la igualdad moral, pero no todas ellas son igualmente aceptables. La legitimidad moral de la justicia distributiva no puede provenir únicamente de la legitimidad del procedimiento, sino que debe incluir al resultado. La igualdad moral es la base y la meta de la justicia, mientras que el procedimiento es sólo la forma de conectar ese proceso. Un procedimiento incorrecto desorienta el sentido último de la justicia, pero la justicia del procedimiento no garantiza la justicia 
del resultado. No se trata de someter el procedimiento al resultado, porque entonces se perdería el sentido moral de la deliberación, sino de impedir que cualquier resultado sea posible. Para que este límite funcione, deben haber más restricciones morales al procedimiento de las que aprueba el utilitarismo.

Entre nosotros, podemos encontrar otra forma de defender al utilitarismo contra las críticas de origen kantiano de Rawls o Dworkin que consisten en priorizar el derecho sobre el bienestar. Esperanza Guisán nos recuerda que el utilitarismo es capaz de reinterpretar el derecho y el bienestar para impedir que los individuos y las minorías queden a merced de las preferencias mayoritarias. Guisán tiene razón cuando nos advierte que detrás de los derechos hay siempre una preocupación por el bienestar, que los derechos no surgen de la nada, no son un a priori independiente de los sentimientos y el interés por el bienestar de las personas. Como ella desea señalar, la idea de dignidad representa nuestro interés por minimizar el sufrimiento, el término libertad esconde en realidad el deseo de desarrollar sin trabas nuestra personalidad, y la igualdad, para evitar ser absolutizada, debe relacionarse con la empatía, con la consideración y el cuidado de los otros ${ }^{16}$.

Sin embargo, no creo que eso transforme al utilitarismo en una teoría adecuada de la moralidad y de la justicia distributiva. Es cierto que la igualdad exige empatía. Si no nos creemos que debemos respetarnos mutuamente y que debemos compartir de manera razonable los recursos escasos para que nadie salga muy perjudicado, la igualdad es un ideal vacío. Pero a la hora de distribuir los recursos en función del bienestar o de las necesidades, deberíamos poder señalar cuáles son las necesidades moralmente relevantes y quiénes son los sujetos de esas necesidades. Y si lo hacemos preguntando directamente a los individuos, como exigiría un utilitarismo com- prometido con la igualdad de todos los puntos de vista sobre lo que es una buena vida o el bienestar subjetivo, entonces el dominio de los prejuicios es infranqueable. Haría falta una distinción objetiva acerca de la bondad de los diversos bienestares, previa a cualquiera declaración subjetiva de los individuos, que nos dijera qué tipo de bienestar merece ser promovido y qué otro tipo hay que marginar. Haría falta, después de todo, priorizar una idea de lo correcto sobre la idea de bienestar.

Guisán nos recuerda, en este punto, que el tipo de bienestar que los liberales kantianos denostan, con razón, es el bienestar volitivo o espontáneo, «los intereses o deseos que nacen de lo establecido, la ignorancia y la inercia», pero ignoran que una parte del utilitarismo, encabezada por Stuart Mill, no tiene inconveniente en privilegiar el bienestar ilustrado, crítico o moral, «los deseos esclarecidos que vienen de la ilustración y la diligencia en el auto-desarrollo» ${ }^{17}$. El bienestar ilustrado se consigue tras una reflexión crítica sobre los propios deseos, incluidos los más espontáneos, de manera que lo que realmente deseo puede no coincidir con mis deseos más inmediatos.

Sin embargo, en perjuicio de las buenas intenciones de Stuart Mill y de la propia Esperanza Guisán, ni siquiera el bienestar ilustrado o el bienestar moral (la capacidad de estar bien con uno mismo y con los demás) pueden evitar que alguien entienda (incluso tras haberlo meditado a conciencia) que sólo estará bien consigo y con los demás si las personas o grupos humanos que él o ella considera de rango inferior no tienen acceso a determinados privilegios. La búsqueda de un bienestar objetivo debería llevarse a cabo hasta sus últimas consecuencias si queremos consolidar la igualdad moral en la justicia distributiva. No basta con distinguir placeres espontáneos de placeres ilustrados. Si queremos incorporar el placer o el bienestar en la métrica distributiva, debemos marcar cla- 
ramente la frontera entre los placeres que perjudican injustamente a otras personas y el resto de los placeres. Pero, para esta empresa, la teoría utilitarista de la justicia no nos sirve, puesto que una definición clara y precisa del bienestar o de las necesidades moralmente correctas socavaría el compromiso fundamental de la teoría con la imparcialidad moral en la concepción del bienestar.

Otra línea de defensa de la concepción utilitarista de la persona proviene del debate sobre la identidad personal. Derek Parfit es el autor más destacado en este ámbito. Parfit entiende que la concepción moral de la persona depende en buena medida de la identidad personal. Cree que es importante admitir esa estrecha relación y añade que si se puede demostrar que la teoría utilitarista de la justicia encaja mejor con una concepción correcta de la identidad personal, entonces las objeciones al utilitarismo que presuponen una visión equivocada de la identidad personal se desacreditarían a sí mismas. Parfit distingue dos grandes concepciones de la identidad personal: la reduccionista y la no-reduccionista. El Reduccionismo considera que la identidad personal se reduce a una continuidad física y psicológica de la persona. La continuidad psicológica puede no ser perfecta, por lo que podemos hablar de grados de continuidad. El No-reduccionismo, en cambio, afirma que la identidad personal se construye a partir de algún hecho que está situado más allá de la continuidad física y psicológica. Para Parfit, ante la imposibilidad empírica de encontrar ese hecho, tenemos que aceptar el Reduccionismo como la concepción de la identidad personal más acertada, lo que nos obliga, a su vez, a asumir ciertas consecuencias morales.

Aceptar el Reduccionismo tiene unas implicaciones sobre la moralidad que modifica sustancialmente nuestra concepción moral de la persona. Por un lado, aparecen problemas respecto a la responsa- bilidad moral de los individuos. Si la identidad personal equivale a la continuidad física y psicológica, un grado bajo de esa conexión debilita la responsabilidad individual. Por ejemplo, el yo actual podría no ser totalmente responsable de los actos del yo del pasado y, por tanto, podría no estar vinculado a los compromisos adquiridos en el pasado por el yo antiguo. En ese caso, ipodemos mantener que los delincuentes merecen ser castigados en el presente por actos cometidos hace tiempo? Dependerá de cada caso, pero sin duda la noción de responsabilidad individual queda seriamente desvirtuada.

Por otro lado, la concepión reduccionista de la identidad personal tiene efectos importantes sobre la justicia distributiva. Parfit sabe que la justicia distributiva presupone una idea de igualdad moral, y asume que ésta requiere que las personas estén moralmente separadas entre sí, es decir, siguiendo el consejo kantiano, que nadie debería sacrificar su individualidad en nombre de la colectividad ${ }^{18}$. Sin embargo, Parfit añade que si aceptamos la separabilidad de las personas, entonces debemos abrazar una concepción no-reduccionista de la identidad personal, puesto que la individualidad exige un compromiso con algún hecho profundo (deep further fact) situado más allá de la continuidad psicológica.

Pero aquí aparece un serio problema. $\mathrm{Si}$ el Reduccionismo es filosóficamente más razonable que el No-reduccionismo, y si la igualdad moral está ligada sólo a este último, entonces ¿qué lugar debe ocupar ahora la igualdad? La respuesta es descorazonadora. El Reduccionismo ignora la individualidad, no encuentra ninguna razón de peso que nos permita saber con claridad que una persona es siempre la misma a lo largo del tiempo. En consecuencia, si la individualidad se desvanece, los principios distributivos que la presuponen también pierden sentido. ¿Quiénes son los sujetos receptores, independientes 
entre sí? Sin la individualidad los principios distributivos pierden razón de ser, y pueden ser lógicamente subsumidos bajo los principios maximizadores que caracterizan al utilitarismo.

Sin embargo, eso no significa que la teoría utilitarista de la justicia sea más plausible que las teorías de la justicia que presuponen el No-reduccionismo. Después de todo, alguien que no esté comprometido con el utilitarismo puede decir que, incluso si aceptamos el Reduccionismo, las personas seguimos siendo diferentes. La continuidad psicológica afecta más a la vida interior de los individuos que a la vida entre los individuos ${ }^{19}$.

Ahora debemos retroceder hasta el punto de partida de este apartado: ¿qué concepción moral de la persona esconde finalmente el utilitarismo, que incorpora, como ya sabemos, una visión reduccionista de la identidad personal? La respuesta ya nos es conocida: la persona no existe como una entidad moral diferenciada del bien social. No podemos establecer una distinción moral relevante que justifique la frontera entre las personas. La misma idea de personalidad moral es una construcción engañosa. La persona no es una fuente de reclamación moral más allá de su capacidad de producir utilidad. Eso no significa que la persona no exista. «Creemos que la existencia de una persona no implica nada más que la ocurrencia de unos acontecimientos mentales y físicos (...) Negamos que una persona sea una entidad cuya existencia es separable de su cerebro y de su cuerpo, y de la ocurrencia de sus acontecimientos» ${ }^{20}$. El individuo y la comunidad se funden en una misma masa moral indiferenciada. «Según mi opinión, la visión utilitarista se puede basar, no en la disolución de la persona, sino en su parcial desintegración. Puede descansar en el punto de vista de que la vida de una persona es menos profundamente integral de lo que la mayoría de nosotros asumimos. Los utilitaristas pueden tratar los beneficios y las cargas, no como si se produjesen en el interior de una persona, sino como si no existiese una diferencia moral allí donde se producen. Y esta creencia se puede basar en parte en la idea de que la unidad de cada vida, y, por tanto, la distinción entre las vidas, es en sí misma menos evidente» ${ }^{21}$.

El utilitarismo es impersonal, pero no sólo porque la personalidad se diluya en la colectividad, como sugiere Rawls, sino también porque se deriva de una concepción reduccionista de la identidad personal. El Reduccionismo deslegitima la distribución compensatoria entre individuos, así como intra individuos. Si no disponemos de ningún hecho profundo situado más allá de la continuidad psicológica, no podemos justificar la compensación entre las diferentes partes de la vida de una persona.

La concepción utilitarista de la persona nos ha mostrado la impersonalidad, la indiferenciación de las personas como unidades morales. Y, aprovechando los argumentos de Parfit, he comprobado que es justamente la impersonalidad lo que insensibiliza al utilitarismo sobre los aspectos distributivos y la igualdad. La concepción moral de la persona en el utilitarismo resulta así inadecuada para la justicia distributiva.

La cuestión que nos quedaría pendiente es la siguiente: ise puede mantener la confianza en la posibilidad de la justicia distributiva a pesar de estar comprometido con una visión reduccionista de la identidad personal? La respuesta que puedo dar comienza negando la importancia de la pregunta. No creo que tengamos argumentos fuertes - como los que propone Parfit- que nos obliguen a relacionar tan estrechamente los conceptos de identidad personal y de justicia distributiva. La identidad personal es un problema propio de la filosofía de la mente, no de la filosofía moral. Y a pesar de que sin duda el asunto de la identidad personal es uno de los más 
importantes de su disciplina, el hecho de que hasta hoy se haya mostrado filosóficamente irresoluble apoya la idea de no considerarlo tan importante como para rechazar la idea de una identidad moral de las personas. Al fin y al cabo, la mayoría de nosotros seguimos creyendo las palabras de Rawls cuando declara que «aun así, y por acogernos al ejemplo del texto, supongo que todos estaremos de acuerdo en que, a efectos de la vida pública, Saúl de Tarso y san Pablo el Apóstol son la misma persona. La conversión es irrelevante desde el punto de vista de nuestra identidad pública o institucional» ${ }^{22}$.

\section{La antropología moral rawlsiana}

En respuesta a la teoría utilitarista de la justicia han surgido los igualitarismos liberales contemporáneos, desde los bienestarismos matizados de Arneson ${ }^{23}$, Cohen ${ }^{24}$, Roemer ${ }^{25}$ y Sen ${ }^{26}$ hasta los recursismos ${ }^{27}$ más sobresalientes que representan Dworkin ${ }^{28}$ y Rawls. Pero es sin duda este último quien con mayor maestría ha argumentado en oposición al utilitarismo y ha puesto las condiciones de reflexión que han seguido sus colegas liberales. Por otro lado, si hay algo que une a los diferentes igualitaristas liberales es su concepción de la igualdad moral, centrada en una visión kantiana de la moralidad, que incluye una determinada concepción de la persona, la libertad y la igualdad, como enseguida pondré de manifiesto.

Como ya hemos visto, el utilitarismo elimina la individualidad diluyéndola en la masa indiferenciada de la comunidad. Es como reacción a esa impersonalidad que se tienen que entender, sobre todo, las críticas de Rawls y de Dworkin, seguramente los más kantianos del grupo de los igualitaristas liberales. La no-separabilidad de las personas enciende la objeción rawlsiana a favor de la individualidad y la respon- sabilidad personal sobre el origen y la satisfacción de las preferencias. En el caso de Dworkin, la desaprobación al utilitarismo se centra en su incapacidad para distinguir entre las preferencias externas y las personales. Ambas críticas coinciden, pues, en un mismo objetivo: el de salvaguardar la libertad individual contra la voluntad colectiva.

¿Cómo lo consiguen? Afirmando la persona moral en su individualidad y llenándola de nuevos contenidos morales. Básicamente, la concepción liberal-igualitarista reincorpora las ideas de autonomía y de responsabilidad en el individuo. Un texto de K. Arrow sirve a Rawls para confirmar la ausencia de individualidad y de autonomía en la persona desnuda (bare person) del utilitarismo: «Reducir al individuo a una lista especificada de cualidades es negar su individualidad en un sentido profundo. De una forma que no puedo expresar bien y de cuya defensa tampoco estoy muy seguro, la autonomía de los individuos, un elemento de inconmensurabilidad entre las personas, parece ser negada por la posibilidad de comparaciones interpersonales» ${ }^{29}$. Sin embargo, Rawls cree que Arrow no distingue todavía la individualidad de la autonomía ${ }^{30}$. No es suficiente afirmar la individualidad de la persona, también hay que reconocer su capacidad para erigirse en fuente de moralidad. Para llevar a cabo este segundo paso, Rawls rechaza la concepción bienestarista de la persona que impregna al utilitarismo y la sustituye por una visión kantiana que acentúa la autonomía como la garantía de la libertad y la igualdad moral del individuo.

La autonomía, a su vez, conduce a la idea de responsabilidad. Si el individuo posee autonomía moral, se le puede responsabilizar por la satisfacción de sus deseos. El utilitarismo no incorpora esa idea de responsabilidad personal porque no se plantea ningún tipo de evaluación moral sobre la bondad de las preferencias. Éstas son tan soberanas desde el punto 
de vista político y ético como impermeables a la crítica moral. Solamente el reconocimiento de la autonomía moral del individuo permite poderle responsabilizar por la satisfacción de sus deseos, porque la autonomía moral incorpora una idea de igualdad moral más amplia o sustantiva que la igualdad formal del utilitarismo.

La autonomía y la responsabilidad morales presiden la concepción rawlsiana de la persona. La concepción moral de la persona puede ser considerada como el núcleo de la teoría de la justicia en Rawls ${ }^{31}$. Él insiste reiteradamente en que su concepción de la persona moral se tiene que adecuar a la concepción política de la justicia. De esta manera, el liberalismo político de Rawls quiere eludir las concepciones perfeccionistas o metafísicas de la justicia que se basan en alguna doctrina religiosa, filosófica o moral. Con el objetivo de diseñar una concepción de la justicia que logre el consenso ${ }^{32}$ de todos los miembros razonables ${ }^{33}$ de la sociedad, Rawls cree necesario partir de una concepción política de la justicia que incluya, a su vez, una concepción política de la persona moral.

Como se sabe, la concepción política de la justicia tiene tres características. En primer lugar, es una concepción moral que se tiene que aplicar exclusivamente a las instituciones sociales, políticas y económicas o, en términos rawlsianos, a la estructura básica de la sociedad. En segundo lugar, y aunque se trata de una concepción moral, adopta un punto de vista independiente (freestanding view) respecto a las distintas visiones del bien. El objetivo es evitar el totalitarismo ético en que caen el utilitarismo y las formas de perfeccionismo en la definición de la justicia. Finalmente, Rawls fundamenta el punto de vista independiente en la cultura política de las sociedades democráticas. La concepción política de la justicia no quiere responder a ninguna doctrina metafísica, sino que pretende ser una mera derivación de la cultura política que todos los demócratas comparten. La base de la justicia no es un modelo perfeccionista del ser humano o una intuición ilustrada, sino un hecho histórico.

La concepción política de la justicia se concibe, pues, como un hecho. A partir de aquí, hay que encontrar la fórmula que articule las instituciones liberales y democráticas para desocultar los principios de la justicia que se encuentran latentes en nuestra cultura. La base de esta fórmula es reconocer que, de hecho, en la cultura política de nuestra sociedad democrática compartimos una específica concepción moral de la persona capaz de imponerse, dentro de la concepción política de la justicia, a todas las visiones metafísicas del individuo y de la sociedad.

Para Rawls, esta concepción política de la persona se identifica con el ideal del ciudadano democrático, un ciudadano que es libre e igual. La persona es libre en tres sentidos. En primer lugar, porque se reconoce a sí misma la facultad moral de concebir el bien, con la opción de poder cambiar la idea del bien siempre que lo considere oportuno. Por ese motivo la concepción de la persona no está sujeta a una idea específica del bien. Lo valioso para la vida humana se puede modificar con el tiempo. En cambio, estas modificaciones no alteran la personalidad moral del ciudadano, que permanece estable dentro de la concepción política de la justicia. Se garantiza así que los derechos básicos de la persona no se puedan ver alterados con las transformaciones en la idea del bien, porque están ligados al hecho fundamental de la igualdad moral. Además, permite que la identidad moral de la persona pueda combinar los compromisos morales de la vida pública, presididos por los derechos y los deberes del ciudadano, con los compromisos morales en su vida privada. Estos últimos pueden variar sin que el cambio afecte a los primeros. 
En segundo lugar, las personas son libres porque se ven a sí mismas como fuentes autolegitimadoras (self-authenticating sources) de exigencias morales válidas, es decir, como creadoras y evaluadoras de principios morales. Al margen de toda autoridad y jerarquía social, cada persona es autónoma para juzgar su propia moralidad.

En tercer lugar, y dada la autonomía moral, las personas son libres porque se responsabilizan de sus fines y sus preferencias. Las personas no son portadoras pasivas de deseos, como en el utilitarismo, sino que tienen la capacidad de asumir responsabilidad sobre sus objetivos morales. Son responsables de ajustar sus deseos al conjunto de recursos que con justicia (después de actuar los principios de la justicia) les corresponden.

La concepción moral de la persona tiene además los atributos de racionalidad y razonabilidad. Ambos son también herencia de la filosofía kantiana. Así, la racionalidad o capacidad de perseguir el propio bien y la razonabilidad o capacidad de tener un sentido de la justicia son una derivación del concepto de autonomía moral en Kant. La exigencia kantiana de autonomía queda reflejada en el velo de ignorancia de la posición original, donde las personas están impedidas para escoger principios heterónomos de la justicia. La persona que hay detrás del velo de ignorancia no es un sujeto empírico, sino, parafraseando a Kant, «el sujeto de los fines, es decir, el ser racional mismo, que nunca se tiene que poner como fundamento de las acciones como un simple medio, sino como suprema condición limitativa en el uso de todos los medios, es decir, siempre al mismo tiempo como un fin» ${ }^{34}$. Además, de la misma manera que, en Kant, los principios de la conducta moral que la persona autónoma se da a sí misma obligan en forma de imperativo categórico, «los principios de la justicia son también categóricos en el sentido kantiano (...) actuar a partir de los principios de la justicia es actuar a partir de imperativos categóricos en el sentido de que se aplican a todos nuestros objetivos particulares» ${ }^{35}$. Los principios de la justicia ejercen como imperativos categóricos porque las personas que los escogen son plenamente autónomas en las condiciones ideales de la posición original.

La persona que se esconde tras el velo de ignorancia es, pues, el sujeto trascendental kantiano. Recordemos que el sujeto kantiano es trascendental por dos motivos: uno epistemológico y otro moral. El argumento epistemológico dice, brevemente, lo siguiente: no puedo conocer nada sin darme cuenta de que es un yo quien conoce. Por tanto, introspectivamente, la persona descubre un yo portador de sus experiencias, el lugar donde ocurren los deseos, las inclinaciones, las disposiciones, etcétera. Ahora bien, esta autoconciencia se ve limitada por las constricciones kantianas del conocimiento humano. No podemos conocer qué hay detrás del objeto de las experiencias, porque de algo así no podemos tener ninguna experiencia. Sin embargo, necesitamos presuponer una unidad del yo detrás del objeto de las experiencias, unidad que configura al sujeto. Dado que no podemos conocer al sujeto - porque sólo podemos conocer a través de la experiencia-, pero éste es condición de posibilidad del conocimiento, hablamos de un sujeto trascendental.

$\mathrm{Si}$ el argumento epistemológico presupone la individualidad como condición de posibilidad del conocimiento, el argumento moral la presupone como condición de posibilidad de la acción moral. Como objeto de experiencias, la persona está determinada por las leyes naturales. En cambio, el sujeto de experiencias, que habita en el mundo inteligible, más allá de toda experiencia, es libre de las cadenas de las determinaciones naturales y, en consecuencia, puede ser plenamente autónomo. El sujeto dispone de autonomía plena para darse a sí mismo las leyes morales y obligarse, por 
deber, a cumplirlas. Sólo en este sentido la persona es libre, porque es capaz de una acción moral que no está determinada por la causalidad de la naturaleza.

En Kant, pues, la libertad y la autonomía de la persona nacen del sujeto trascendental, un concepto formal de persona que no se compromete con ninguna idea sobre el bien o sobre la finalidad de las acciones morales. Cuando nos pensamos como personas libres, no nos podemos pensar como seres empíricos. La libertad y la autonomía moral son conceptos formales e independientes de la experiencia, aunque indesligables de la personalidad moral.

Rawls recoge el concepto kantiano de persona moral y lo traslada del mundo inteligible a la posición original. Los principios de la justicia surgen de la elección necesaria de unas personas que, detrás del velo de ignorancia, son libres e iguales en el sentido kantiano. Esto quiere decir que la fuerza de su elección es equivalente a la del imperativo categórico. Rawls entiende que la principal virtud de una teoría de la justicia ha de ser salvaguardar los intereses esenciales de la persona, intereses que han de quedar al margen de la negociación entre las preferencias y deseos que las personas se forman en el mundo. La mejor protección de esos intereses esenciales se produce velando por la igual autonomía y libertad individuales que recoge el primer principio de la justicia y que (insisto en ello) deriva por deducción del máximo interés moral de los miembros de la posición original: el interés de proteger la autonomía y la libertad de la persona respecto de las conveniencias del colectivo o de individuos que no quisieran respetar esa igualdad básica en la autonomía y la libertad. Los principios rawlsianos de la justicia adoptan la forma del imperativo categórico kantiano para poder garantizar la igualdad moral, y lo hacen a partir de una concepción moral de la persona que sigue a la kantiana en con- siderar, como interés supremo de la persona, la autonomía moral y la libertad.

No obstante, y a pesar de su reconocido kantismo, Rawls se aparta de la concepción kantiana de la persona en el rechazo a su idealismo. La persona rawlsiana se encuentra más cerca del mundo inteligible que del sensible, pero no hasta el punto de ignorar los hechos generales que caracterizan a una comunidad. El ser nouménico kantiano no necesita del mundo material para expresarse moralmente. En cambio, la persona rawlsiana, sin abandonar la abstracción de la trascendentalidad kantiana, requiere de un contexto social, político y económico en el que poderse desarrollar.

Por este motivo, los miembros de la posición original, si bien desconocen sus circunstancias particulares, no ignoran los aspectos generales de la justicia. Gracias a ese conocimiento, que no se queda oculto bajo el velo de ignorancia, se dan cuenta de la racionalidad o ventaja mutua de cooperar entre sí, dada la condición de escasez moderada que cubre un amplio abanico de situaciones sociales. Además, «se da por supuesto que conocen los hechos generales de la sociedad humana. Entienden las cuestiones políticas y los principios de la teoría económica; conocen las bases de la organización social y las leyes de la psicología humana» ${ }^{36}$. Este argumento, planteado en su origen en $A$ Theory of Justice cuando Rawls dibuja a la persona que forma parte de la posición original, se amplía en Political Liberalism definiendo a la sociedad humana en términos históricos. De esta manera, la persona moral de origen kantiano convive, en la teoría de la justicia de Rawls, con la tradición de una sociedad democrática.

El sujeto trascendental parece perder así su carácter metafísico y pasa a convertirse en meramente político, porque no tiene otro destino que la sociedad política que le legitima y le acoge. El mensaje de Rawls es, pues, puramente político: si deseamos definir los principios de la jus- 
ticia de una sociedad democrática, el argumento contractualista que incorpora la concepción política de la persona moral es el más adecuado. La persona política no se identifica así con la universalidad kantiana de los seres racionales, sino con el ideal político de la ciudadanía democrática.

Sin embargo, con la concreción histórica del individuo moral parece que también se merma la universalidad moral kantiana en un sentido general. Las sociedades sin una tradición democrática no podrían asumir, o lo harían sólo parcialmente, una concepción moral de la persona como la que el filósofo de Harvard propone. El ideal universalista de persona moral como base de la igualdad pierde así fuerza categórica. Ésta ${ }^{37}$ y otras objeciones a la concepción rawlsiana de la persona como base de la igualdad moral y de la justicia distributiva son la materia del siguiente apartado.

\section{Objeciones a la antropología moral rawlsiana}

Existen dos importantes motivos que explican la testarudez de Rawls por priorizar, en su concepción moral de la persona, lo correcto sobre lo bueno: una visión antiperfeccionista de la justicia y la atribución de responsabilidad personal a los individuos. En el primer caso, el objetivo es evitar el dominio político de alguna forma de perfeccionismo. El perfeccionismo, tal como él lo define, identifica los intereses o las necesidades esenciales de la persona con una visión particular del bien o de perfección humana. En consecuencia, una teoría de la justicia basada en una concepción perfeccionista de la persona o de la sociedad debería promover esa visión particular del bien por encima de cualquiera otra. Sin embargo, una sociedad de ese tipo, dominada políticamente por una idea excluyente de bienestar o de felicidad, pro- vocaría severas injusticias en las personas que no comparten esa idea. Por esa razón, Rawls apuesta por una concepción política de la persona y de la justicia, para no comprometerse con una idea perfeccionista del bien que le llevaría a tener que afirmar una sociedad injusta. En el segundo caso, la prioridad de lo correcto sobre lo bueno permite, además, que los ciudadanos se responsabilicen de sus deseos y preferencias, puesto que todo tipo de deseo o de acción personal que persiga una idea determinada y particular del bien deberá ajustarse a las exigencias de lo correcto. Se quiere evitar así, por ejemplo, que las opiniones mayoritarias o muy intensas que en un momento dado dominen la vida social sobre el sexo, las relaciones humanas o los privilegios de las mayorías y los grupos de poder se impongan a una concepción previamente pactada en una situación presidida por juicios meditados entre personas iguales.

Los críticos a Rawls han encontrado un terreno fértil en la prioridad de lo correcto sobre lo bueno para lanzar sus ataques. Algunos de esos críticos son liberales que se apartan de la doctrina rawlsiana ${ }^{38}$, pero la mayor parte pertenecen a la corriente comunitarista. La objeción comunitarista de Michael Sandel a la concepción rawlsiana de la persona es una de las más destacadas. Sandel argumenta que Rawls no puede mantener una concepción moral de la persona independientemente de las éticas o valores específicos de la comunidad sin caer o bien en un formalismo abstracto y carente de sentido desde un punto de vista moral o bien en la contradicción de suponer una unidad moral del yo previa al único contexto que puede configurar concepciones morales en el individuo: la comunidad. Para Sandel, no es posible definir una unidad del yo independientemente de que ese yo pertenece a una comunidad histórica particular que le identifica y le dota de finalidades morales. Los valores no son un sistema de preferencias 
que la persona escoge libremente. La persona no es independiente de sus valores, como éstos no son independientes de la comunidad que los crea. Para Sandel, un yo separado de sus finalidades, el yo deontológico de Rawls, «privado completamente de su carácter, es incapaz de autoconocimiento en un sentido moralmente relevante. En tanto que el yo aparece desencarnado y esencialmente desposeído, la deliberación sobre los fines propios puede ser un ejercicio de arbitrariedad» ${ }^{39}$. Recuperando una expresión de Alasdair MacIntyre, otro comunitarista como Sandel, se puede decir que para los comunitaristas la persona moral rawlsiana es un fantasma, y los fantasmas no existen ${ }^{40}$.

Otros autores de la órbita comunitarista han dirigido sus críticas a la concepción rawlsiana de la persona. Así, por ejemplo, Charles Taylor discrepa de la idea kantiano-rawlsiana del punto de vista imparcial de la moralidad individual. No es posible que la persona pueda adoptar un punto de vista imparcial sobre la moral y la justicia aun habiendo deliberado correctamente sobre todos los valores en juego. Según él, la persona está imbuida de una diversidad de aspectos morales (diversity of goods), como la integridad personal, la compasión, la justicia, la amistad, la liberación, etcétera, que no puede unificar coherentemente en un plan racional de vida dominado por la justicia. La incompatibilidad entre estos diversos bienes morales es demasiado común como para dar opción a una unidad permanente de criterio $^{41}$. Bernard Williams, por su parte, cree que la imparcialidad no resulta una interpretación adecuada de la justicia porque representa deficientemente el dominio de los fenómenos morales. En consecuencia, «el hábito de la filosofía moral, particularmente en su forma kantiana, de tratar a las personas en abstracto respecto a su carácter, no es tanto un mecanismo legítimo para afrontar un aspecto del pensamiento como una interpretación erró- nea, porque omite tanto lo que limita como lo que ayuda a definir este aspecto del pensamiento» ${ }^{42}$.

Sin embargo, dudo que esas críticas sean efectivas en sus propósitos, sobre todo porque no veo la importancia de debatir si la persona que Rawls presupone como base de la concepción de la justicia existe de hecho o no. La existencia empírica de la persona rawlsiana no es necesaria para legitimar la teoría de la justicia que Rawls propone. Como él mismo declara, «nuestro razonamiento no nos compromete con una doctrina metafísica particular acerca de la naturaleza del yo más de lo que nuestra participación en una obra teatral, haciendo, pongamos por caso, de Macbeth, o de Lady Macbeth, nos comprometería a pensar que somos realmente un rey o una reina embarcados en una lucha desesperada por el poder político» ${ }^{43}$

Lo que es importante en la concepción moral de la persona no es su presencia encarnada, sino su capacidad para representar la imagen sobre la que se debe proyectar nuestra concepción de la igualdad moral. Eso no significa que debamos ignorar los aspectos psicológicos de la personalidad moral. Una teoría filosófica o ética que imaginase a una persona que piensa y actúa de forma contraria a los dictados de la psicología la invalidaría como teoría normativa. Pero una teoría normativa sobre la personalidad moral no se debe reducir a la psicología moral. Es normativa porque quiere proyectar una imagen moral del tipo de persona que vale la pena ser y, como consecuencia, de los atributos morales de la persona que vale la pena defender y proteger colectivamente. Por esa razón, creo que la crítica comunitarista a la personalidad moral rawlsiana no altera el propósito de Rawls.

Por otro lado, Rawls no pretende que su concepción de la persona, la imagen sobre la que proyectar nuestro sentido de la igualdad moral, dependa de algún tipo de verdad ética, sino de la legitimidad 
pública. Ahora bien, hay que tener en cuenta que ésta no se adquiere sociológicamente, es decir, a través de un consenso fáctico, sino moralmente, a través del compromiso con una determinada idea de la persona que Rawls espera que obtenga el máximo reconocimiento público dentro de una cultura democrática occidental. Por esa razón, creo que lo importante tampoco no es discutir, como quiere el comunitarismo, si la concepción rawlsiana de la persona responde a una idea metafísica o estrictamente política. El debate debería centrarse en saber si realmente estamos de acuerdo con Rawls en que la prioridad moral de la justicia distributiva debe estar centrada en la protección de la capacidad de las personas para formar, revisar y modificar los valores que la vinculan con la sociedad. Dicho de otra manera: no me interesa tanto si la idea de autonomía moral responde a un ideal metafísico de la persona, como cree el comunitarismo, o si se puede reducir a un ideal meramente político, como mantiene Rawls; lo que considero que merece más nuestra reflexión es saber de qué modo debemos entender la autonomía moral de la persona, dentro de las prioridades de la justicia distributiva, cuando entra en colisión con otros valores como el bienestar o las necesidades humanas. Si la defensa de la autonomía nos vela el interés de las personas por satisfacer sus necesidades básicas de bienestar, si la protección de la autonomía nos aleja de la satisfacción de las necesidades básicas de los seres humanos, entonces habrá que poner en duda si la estrategia rawlsiana de fundamentar la justicia en un ideal de persona excesivamente ligada a la libertad formal es la que mejor representa nuestras intuiciones éticas sobre la igualdad moral.

A medio camino entre el comunitarismo y el liberalismo, Dworkin ha propuesto una particular e interesante concepción de la moralidad pública. Como buen liberal, comparte con Rawls el deseo de que la acción del Estado se mantenga neutral res- pecto a las concepciones personales del bien, pero admite que este tipo de neutralidad no se puede basar en un antiperfeccionismo político, porque $-\mathrm{y}$ aquí Dworkin se coloca del lado de los comunitaristas- detrás de toda concepción de la justicia tiene que haber un compromiso ético individual que dé fuerza categórica a los mandatos del derecho. La fundamentación de la concepción rawlsiana de la persona en los ideales «latentes en la cultura pública de una sociedad democrática» es insuficiente para obtener un sólido consenso moral, ya que, según Dworkin, la historia de toda comunidad incluye tanto la tradición como la controversia.

Dworkin cree haber encontrado esa fuerza categórica en una ética del desafío (que, según él, debería caracterizar a todo liberal) que tiene su contrapunto en una ética del impacto ${ }^{44}$. El perfeccionismo y el utilitarismo siguen una ética del impacto para llegar a los principios de la justicia. Usar el bienestar, las preferencias o las virtudes morales como el criterio de la justicia supone valorar la bondad de una vida en función de las consecuencias o el impacto de esa vida en el mundo. El impacto producido por la vida de una buena persona es la diferencia que su vida produce en el valor objetivo del mundo. La idea es que una vida puede tener más o menos valor no porque vivirla de una manera particular sea intrínsecamente valioso, sino porque vivirla así tiene mejores consecuencias que vivirla de otra forma.

En cambio, la ética del desafío no otorga la bondad de una vida a las consecuencias que ésta tiene en el mundo, sino que adopta el punto de vista aristotélico que afirma que una vida buena posee el valor inherente de un ejercicio ejecutado con destreza. La bondad de una vida reside en la superación del desafío de vivir. Por tanto, el objetivo de la justicia basada en la ética del desafío no puede ser ni aumentar ni igualar el bienestar de las personas. Toda concepción del bienestar supone una 
concepción de los recursos que hacen falta para obtener ese bienestar. Lo que hay que distribuir son los recursos necesarios para afrontar los desafíos, y puesto que la igualdad moral exige tratar con igualdad a todas las personas en lo que es moralmente relevante para llevar una vida buena, la ética del desafío propone que la igualdad de recursos sea la mejor interpretación de la justicia distributiva. La ética del desafío logra, de esta manera, conciliar ética y política en una sola visión liberal e igualitarista de la justicia. Es liberal por cuanto nadie decide en qué debe consistir el desafío de una vida buena excepto la propia persona. $\mathrm{Y}$ cree eludir los ataques comunitaristas a la concepción rawlsiana de la persona por cuanto las personas que se comprometen con la ética del desafío son personas reales, a diferencia de los miembros de la posición original en Rawls. Son personas que, desprovistas de cualquier tipo de velo, saben todo lo que la gente real sabe sobre sus propios intereses, convicciones y situaciones. Lo único que ahora hace falta para que la ética del desafío funde una teoría de la justicia basada en la igualdad de recursos es que sea ampliamente compartida por los miembros de la sociedad. Dworkin cree que todos los ciudadanos de talante liberal deberían entender que la ética del desafío representa adecuadamente sus convicciones sobre la mejor forma de combinar la moral pública (la justicia) y la moral privada ${ }^{45}$.

La personalidad moral no puede ser un ideal que compartimos de forma abstracta pero que no seguimos en nuestro comportamiento cotidiano. Para Dworkin, el liberal ético es alguien que, además de tener un interés básico en perseguir su propio bien, no desea más recursos de los que le corresponden por justicia. Como persona racional que es, espera que una parte justa de los recursos para él sea la mayor parte posible, pero sabe que eso no le da derecho a negociar a favor de una teoría de la justicia que le asigne, a él, una por- ción mayor. «Eso supondría gratuitamente que tener más está realmente en los intereses de aquellos que, de hecho, tendrán más. Por nuestra parte, no pensaremos que tener más riqueza esté en los intereses de la mayoría a no ser que el esquema de asignación sea justo» ${ }^{46}$. Una teoría de la justicia solamente es buena si se trata de una teoría correcta, pero esa superioridad de lo correcto sobre lo bueno no obedece a una prioridad de la justicia sobre el bien, sino a una fusión de ambos en la figura del liberal ético. Esa fusión permite esquivar la crítica comunitarista que denunciaba a la concepción rawlsiana de la persona por mantener una moralidad pública (basada en las convicciones formales sobre la justicia) escindida de la moralidad privada (dominada por los compromisos personales con la vida buena).

El punto de vista de la concepción política de la persona en Dworkin no es imparcial, como en Rawls. El compromiso político de la persona con la igualdad implica también un compromiso personal con la igualdad en la moralidad privada ${ }^{47}$. La igualdad no puede ser únicamente una cuestión procedimental de elección de principios. Si realmente estamos comprometidos con la igualdad, este compromiso se tiene que reflejar en la perspectiva personal de la justicia.

A pesar de esto, aunque la concepción dworkiniana de la persona difiere de la rawlsiana en cuanto a su naturaleza, creo que se sigue asemejando en cuanto a su contenido moral. Desde el punto de vista de la naturaleza ética de la persona, Dworkin sustituye la persona desencarnada e imparcial por otra comprometida sustancialmente - y no sólo formalmente- con un sentido de la justicia - la que se deriva de la ética del desafío- pero, desde la perspectiva del contenido moral de la persona, mantiene la prioridad de la capacidad de elección entre las diversas maneras de vivir por encima de una concepción más amplia que integre al bienestar y a 
las necesidades humanas. Precisamente ésa es una de las intenciones de Dworkin con su ética del desafío: la de alejar de los criterios de la justicia toda noción referida al bienestar y a las necesidades materiales de las personas. Por eso la concepción ética de la persona desemboca en una igualdad inicial de recursos, previa a toda valoración acerca del bienestar y las necesidades desiguales. E, insistiendo en la prioridad de la autonomía, también mantiene la responsabilidad individual por la satisfacción de las preferencias: eso es lo que le lleva a afirmar que las personas deben responsabilizarse de los recursos que la justicia les entrega (no tienen derecho a más ni a menos recursos de los que les corresponden por igualdad). Con esos recursos deben llevar adelante sus planes de vida.

Sin embargo, esa visión de la justicia se vuelve contra las intenciones igualitaristas del propio Dworkin de no responsabilizar a las personas por las circunstancias que no controla y que, no obstante, influyen en sus planes de vida. Porque, ino es cierto que la libertad de elección de las personas sobre lo que para ellas es una vida buena depende en un grado bastante elevado de su posición en la sociedad y de la conciencia de su capacidad para intentar llevar adelante sus decisiones? Si el tipo de vida que alguien quiere para sí depende del conocimiento de lo que puede hacer y de lo que puede llegar a ser, ino es cierto que hay individuos que tienen un margen de elección más reducido a causa precisamente de ocupar una posición social más limitada en recursos -económicos, sociales, educativos y culturales-? Las preferencias de las personas están determinadas en gran parte por una desigualdad de bienestar y de satisfacción de necesidades que la teoría de la justicia en Dworkin se obstina en ignorar para no caer en los efectos morales perversos que él mismo denuncia en las teorías bienestaristas.
Dworkin distribuye los recursos con igualdad porque únicamente atiende al desafío de llevar adelante una vida buena, desafío que formalmente todas las personas comparten por igual, y espera que esas mismas personas adapten sus preferencias diferentes a esos recursos iguales. Ése es el sentido que Dworkin da a la responsabilidad individual. Pero ignora que esas preferencias no siempre son producto de la libertad de elección, sino que a veces provienen de una libertad condicionada. Me refiero sobre todo a los casos en que las personas adaptan las preferencias a las condiciones objetivas de su entorno inmediato o histórico. Este tipo de preferencias adaptativas se desarrollan racional pero involuntariamente. Son racionales por cuanto buscan el ajustamiento de las aspiraciones individuales a las posibilidades percibidas como reales, pero son, además, involuntarias porque ese ajustamiento viene forzado por las circunstancias y no como resultado de una opción consciente y meditada sobre diversas alternativas efectivamente disponibles. Las preferencias condicionadas por esos factores se pueden convertir en convicciones como consecuencia de los procesos cognitivos que explican las llamadas preferencias adaptativas ${ }^{48}$. La preferencia de los esclavos de no liberarse, la de las mujeres por aceptar un papel de sumisión ante los hombres o la de los niños por reproducir los roles sociales y profesionales de sus padres son ejemplos típicos de esa clase de preferencias. La desigualdad material condiciona injustamente a las preferencias adaptativas. Luego si responsabilizamos por completo a las personas por ese tipo de preferencias, estamos violando el mismo principio que queremos justificar, a saber, que deberíamos igualar las circunstancias sociales y naturales que la persona no ha escogido $^{49}$.

Tanto Rawls como Dworkin se obstinan en defender una concepción de la persona cuya prioridad moral es proteger la auto- 
nomía racional del individuo, es decir, su capacidad para formar, revisar y perseguir las ideas particulares del bien, por encima de cualquiera consideración sobre las necesidades materiales y otras capacidades de las personas. La prioridad de la autonomía moral se justifica políticamente por el temor a los abusos del igualitarismo social. Ese temor queda recogido, por ejemplo, en la tesis rawlsiana sobre el orden lexicográfico de los principios de la justicia, que prohíbe que las libertades individuales se puedan canjear por ventajas socioeconómicas. Cuando en alguna ocasión se ha acusado a Rawls de ser, por esa razón, excesivamente liberal ${ }^{50}$, de acabar defendiendo una idea de libertad demasiado formal $y$ de justificar una amplia desigualdad material ${ }^{51}$, éste ha intentando sacudirse de encima la crítica señalando la conveniencia de priorizar la libertad sobre el valor de la libertad. Más allá de la aplicación de esta última a las libertades políticas, que es la única concesión de Rawls a este tipo de críticas, resulta «irracional, superfluo y socialmente divisorio» garantizar un igual valor de la libertad que suponga mezclar las consideraciones económicas con las libertades ${ }^{52}$.

La prioridad de la libertad sobre el valor de la libertad responde a una primacía ética de la autonomía moral del individuo por encima de otros aspectos morales de la persona como el bienestar, las necesidades o las capacidades. Y esa primacía se debe al deseo de proteger la autonomía moral del individuo contra los abusos del colectivo. Pero ese blindaje de la autonomía impide llevar a cabo su misma finalidad práctica: la libertad de escoger responsablemente una vida buena. Los liberales kantianos no saben reconocer que si la autonomía moral se recoge únicamente en las libertades formales, entonces no se puede asegurar una libertad real de elección. Las elecciones personales, incluidas las elecciones morales, dependen de algo más que de una opción formal o legal, dependen de que existan unas condiciones materiales, educativas, culturales y hasta sanitarias que permitan que las diversas opciones estén efectivamente disponibles para el individuo. No es suficiente con tener el permiso legal de ejercer la autonomía. También es preciso poder ser capaz de llevarla a cabo. Para ello son necesarios recursos económicos — públicos o privados-, habilidades educativas, valores culturales y hasta una buena salud suficientes para ejercer la libertad con seriedad y con responsabilidad. Una teoría de la justicia comprometida con la autonomía moral debería incorporar a la concepción de la persona la satisfacción de las condiciones materiales mínimas o suficientes para el ejercicio completo de esa autonomía. Las personas deseamos decidir por nosotras mismas el tipo de vida buena que queremos llevar, contra cualquier dictado externo, aun el más bienintencionado. Eso debe perseguir la defensa política y ética de la autonomía moral del individuo. Pero esa voluntad es vacía si no podemos llevar una vida libre de impedimentos externos para poder sacar adelante nuestros proyectos morales. Una sólida tradición liberal ha llamado libertad positiva a la primera parte de ese anhelo (soy yo quien controla y determino lo que hago y lo que soy) y libertad negativa a la segunda parte (el ámbito en el que se me deja o se me debe dejar hacer o ser lo que soy capaz de hacer o ser). Sin suficientes recursos materiales y culturales al alcance las personas, la capacidad de hacer o ser lo uno es capaz de hacer o ser es una mera declaración de intenciones. El ejercicio de mis capacidades no depende únicamente de mi voluntad de llevarlas a cabo, sino también de todos esos factores externos que tienen que ver con la economía, la educación, la cultura y la salud.

Eso no significa que debamos invertir ahora, como temen los liberales kantianos, el orden de la prioridad y que, por consiguiente, las condiciones de la libertad 
deban anteponerse a la misma libertad. Resultaría una injusticia aún mayor anteponer el valor de la libertad a la misma libertad. La libertad formal es condición necesaria, aunque no suficiente, de la justicia. Hace falta integrar a los medios de la libertad en la libertad misma. Los medios de la libertad deben sumar, no restar, libertad.

\section{Justicia y perfeccionismo}

Ahora bien, para llevar a cabo la identificación de la libertad con el valor de la libertad en una teoría liberal e igualitarista de la justicia se debe modificar la concepción moral de la persona de origen kantiano que hasta ahora han defendido autores como Rawls y Dworkin. Y el primer paso que deberíamos dar en esa dirección es poner en cuestión su antiperfeccionismo. Pero no, como querrían los comunitaristas, para sustituirlo por una visión moralmente perfeccionista de la persona. La concepción tradicional del perfeccionismo - la que proponen los comunitaristas y contra la cual se enfrentan los liberales kantianos como Rawls y Dworkinconsidera que existen formas de vida más valiosas que otras y, como consecuencia, independientemente de la voluntad de los individuos, propone que el Estado se sienta legitimado para ejercer una coerción destinada a obligar a la gente a alcanzar la excelencia en la forma de vida superior. Paralelamente, los recursos se deberían distribuir con el objetivo de favorecer a los que llevan una vida de excelencia. En esa situación, el elitismo sustituye a la igualdad de oportunidades.

Sin embargo, existe otra forma de concebir el perfeccionismo. El tipo de perfeccionismo que los kantianos rechazan responde a una versión en sentido fuerte, dominada por una visión amplia y completa de las virtudes y la excelencia humanas. En cambio, en su sentido débil, el per- feccionismo puede restringirse a una teoría moral de la naturaleza humana ${ }^{53}$. El perfeccionismo en sentido fuerte viola claramente nuestras intuiciones morales sobre la libertad y la igualdad de las personas. Pero el perfeccionismo en sentido débil, creo que no sólo no pone en peligro la libertad y la igualdad, sino que las estimula y las protege contra las insuficiencias del kantismo.

Aún más, se puede afirmar que, bajo esa distinción, la misma concepción moral de la persona en Rawls o en Dworkin responde al perfil de un tipo de perfeccionismo débil. Las dos facultades morales de la persona rawlsiana o la ética dworkiniana del desafío representan ya una forma de excelencia mínima, un ideal moral que, en el caso de Rawls, afecta a todos los miembros de la cultura democrática occidental, mientras que en Dworkin se restringe a los liberales éticos. En la medida en que ambos defienden sus respectivas teorías morales de la naturaleza humana contra sus posibles competidoras, entran en el debate del perfeccionismo sobre los componentes básicos de la personalidad moral. Otra cosa bien distinta es que sus propuestas resulten inadecuadas desde el punto de vista de la justicia.

En las teorías de la justicia, la igualdad se deriva de una concepción moral de la persona, y ésta representa ya una forma de perfeccionismo, aunque se trate de un perfeccionismo en sentido débil. La justicia, pues, es un principio relativo a la igualdad moral y ésta, a su vez, implica una determinada concepción moral de la persona. Aún más, si no reconocemos algún tipo de perfeccionismo, aunque sea en sentido débil, sobre la naturaleza moral de la persona, no tiene sentido buscar una base moral de la igualdad y de la justicia distributiva.

Llegados a este punto, creo que el debate filosófico sobre la justicia distributiva se debería centrar, entonces, en la bondad de las teorías éticas sobre la naturaleza 
humana como soporte conceptual de nuestras intuiciones morales sobre la justicia. En ese debate, hemos visto que el utilitarismo resulta inapropiado para fundamentar una teoría de la justicia distributiva, pues ni siquiera respeta una de sus condiciones iniciales: el respeto por la individualidad. En oposición al utilitarismo, las teorías de la justicia de Rawls y de Dworkin recuperan la concepción kantiana de la personalidad moral basada en la prioridad de la individualidad y la autonomía. Pero, en su caso, se trata de una individualidad excesivamente formal y exenta de contenidos morales para conectar solidariamente a los seres humanos. Por esa razón, es tan ciega a los aspectos distributivos de la justicia como lo era la ausencia de individualidad en el utilitarismo.

Un ejemplo ilustrativo lo tenemos en el ultraliberal Robert Nozick. Junto a Rawls, Nozick es un ferviente opositor de la concepción utilitarista de la persona, y su principal argumento en contra consiste también, como en el caso de Rawls, en mostrar la impersonalidad del utilitarismo y una de sus más denunciadas implicaciones éticas: la violación de las libertades y los derechos individuales. «Hay sólo personas individuales, diferentes personas individuales, con sus propias vidas individuales. Usar a uno de estos individuos en beneficio de otros es usarlo a él y beneficiar a otros. Nada más... Hablar de un bien social superior encubre esta situación (iintencionalmente?). Usar a una persona en esta forma no respeta, ni toma en cuenta suficientemente, el hecho de que es una persona separada, que ésta es la única vida que tiene. Él no obtiene algún bien predominante por su sacrificio y nadie está facultado a forzarle a esto» ${ }^{54}$. No obstante, Nozick, en su propósito de afirmar rotundamente la individualidad, deriva unas restricciones morales libertaristas que hacen de los individuos islotes incomunicados y desinteresados entre sí, aun perteneciendo a la misma sociedad. En el límite de ese compromiso con la individualidad más insolidaria, Nozick llega a afirmar la inmoralidad de la misma justicia distributiva, que se propone redistribuir (usurpar) bienes privados sobre los cuales individuos libres tienen derechos de propiedad ${ }^{55}$.

$\mathrm{El}$ individualismo de los liberales más igualitaristas como Rawls o Dworkin no confunde la separabilidad de las personas con el aislamiento social, pero su individualismo de origen kantiano no produce suficiente fuerza categórica para fundamentar una teoría de la justicia distributiva que absorba buena parte de nuestras intuiciones morales básicas sobre las exigencias materiales tanto de la autonomía como de la solidaridad interpersonal. Debemos buscar una teoría ética de la naturaleza humana que refleje con más éxito nuestras intuiciones sobre la igualdad moral y que sirva de fundamento para una nueva teoría de la justicia distributiva coherente con esas intuiciones.

Uno de los intentos más sobresalientes que ha producido la filosofía moral contemporánea en este sentido lo representa la obra de Martha Nussbaum. Para esta filósofa norteamericana, los ataques del liberalismo al perfeccionismo ${ }^{56}$ en sentido fuerte están plenamente justificados. Ese tipo de perfeccionismo, que considera que la verdad de la estructura de la realidad es independiente de toda interpretación humana, va en contra de nuestros valores más arraigados sobre la autonomía moral. En consecuencia, una teoría perfeccionista que afirmase que el sexismo o el racismo son naturales y que la sociedad los debe promover contravendría nuestras intuiciones más básicas sobre la igualdad moral. Sin embargo, los críticos de ese tipo de perfeccionismo han extendido injustificadamente sus objeciones a toda clase de perfeccionismo. En cambio - piensa Nussbaum-, las teorías éticas sobre la naturaleza humana que surgen de los factores históricos con el objetivo de definir las necesidades y las funciones humanas bási- 
cas no deberían estar sujetas a las objeciones tradicionales que el liberalismo ha dirigido al perfeccionismo.

$\mathrm{Al}$ igual que Rawls, Nussbaum recupera la perspectiva histórica al trazar los límites de la personalidad moral, pero a diferencia de aquél, abandona el punto de vista kantiano por el aristotélico. Para ella, las fuentes históricas no se deben reducir exclusivamente a los textos y documentos de la tradición política constitucional. Se tienen que ampliar a otras tradiciones (incluidos «los mitos y las historias que sitúan al ser humano en algún lugar del universo») que intentan definir lo que es indiscutiblemente humano. De la visión que a lo largo de la historia las personas han hecho de sí mismas tenemos que extraer los elementos comunes (la humanidad común) que tiene que ver con nuestras capacidades y nuestras necesidades. En este sentido, en consonancia con el liberalismo, el ideal de persona no será metafísico, porque «no pretende derivarse de ninguna fuente externa a las interpretaciones y evaluaciones de sí mismos que los seres humanos han realizado de hecho a lo largo de la historia. Tampoco se trata de recurrir a ninguna metafísica singular o tradición religiosa. Su objetivo es ser tan universal como sea posible» 57 .

La capacidades y las necesidades humanas básicas responden a una concepción del bien que Nussbaum llama concepción amplia y vaga de la persona (thick vague conception of the human being), que se deriva a su vez de una concepción amplia y vaga del bien, en contraposición a la teoría restringida del bien (thin theory of the good) que, en Rawls, coincide con la concepción política de la persona. En la concepción nussbaumiana de la persona, lo correcto no es prioritario a lo bueno, sino que se deriva de la concepción amplia y vaga del bien.

Así pues, a partir del reconocimiento de lo que es históricamente común en el ser humano, Nussbaum elabora una lista de las capacidades humanas básicas que una sociedad liberal comprometida con la igualdad debería tener en cuenta como base de la justicia distributiva. La lista tiende a ser muy pormenorizada. Tal vez en exceso, sobre todo porque el detallismo le ha supuesto numerosas y acertadas críticas sobre la justificación dudosa de algunas de las necesidades básicas universales que en ella aparecen.

Sustancialmente, la lista trata de reflejar que, a lo largo de la historia de la humanidad, las personas han coincidido en necesitar la propia vida, la salud, el alimento y el abrigo, la capacidad de pensar, imaginar, reír, jugar y sentir placer, el afecto y los vínculos familiares y sociales con los demás, y el libre compromiso con una concepción particular de la vida buena. Son unas necesidades y capacidades valiosas por sí mismas, es decir, en el sentido kantiano de la dignidad, no intercambiables entre sí. Para Nussbaum, la satisfacción de esas necesidades básicas representa una condición ineludible de una teoría de la igualdad comprometida tanto con la libertad como con la diferencia. La libertad de elección es una más de las necesidades que tiene el ser humano en su desarrollo moral. Pero la igualdad moral no partiría ahora de la sola y formal libertad de elección, como creen Rawls y Dworkin inspirándose en Kant, sino de la satisfacción de unas necesidades básicas sin las cuales ni siquiera la libertad de elección es posible.

Las ideas de Nussbaum intentan reflejar en parte las tesis de Amartya Sen sobre la justicia social. Sen ha sabido captar la estrecha relación que hay entre la libertad y el valor o los medios de la libertad pero, a diferencia de otros liberales que asocian el valor de la libertad a los recursos económicos, Sen juzga que el valor de la libertad casa mejor con el concepto de capacidades que con el de bienes primarios o recursos económicos. A menudo los recursos económicos no nos otorgan la capacidad de llevar a cabo los propósitos que 
dicta nuestra autonomía moral. Las personas podemos poseer idénticos medios económicos, pero diferir en otros sentidos que se escapan a nuestra responsabilidad y que condicionan nuestra autonomía. Por ejemplo, vivimos en lugares distintos, con condiciones climáticas y de riesgo de epidemias diferentes, poseemos una educación y unos valores culturales divergentes y hasta nuestros cuerpos son desiguales en orden a las necesidades de alimento o de abrigo. Un simple embarazo hace diferentes a unas personas y a otras. Por lo que medir la desigualdad social por la cantidad de recursos económicos disponibles no permite darse cuenta de que existen otros factores que intervienen en la desigualdad. Las personas transformamos los recursos económicos en bienestar de manera diferente en función de nuestras necesidades diferentes, tanto las que nacen de nuestras preferencias como aquellas de las que no somos directamente responsables. Una teoría de la justicia distributiva comprometida con el ideal liberal de responsabilizar a las personas por sus preferencias, pero sólo por las voluntarias, debería poder compensar esas desigualdades basadas en las circunstancias diferentes.

Sin embargo, Sen se ha negado hasta ahora a elaborar una lista con las necesidades y capacidades básicas que la justicia debería igualar. Cree que un intento de especificación en esa dirección desvirtuaría el compromiso liberal con la pluralidad cultural. A pesar de reconocer que la libertad es un mero formalismo sin los medios de la libertad, en la práctica se decanta por favorecer a la libertad para dirimir el conflicto entre ambos, es decir, espera que cada sociedad particular exprese sus preferencias sobre los contenidos de la justicia en el marco de una democracia liberal ${ }^{58}$.

¿Cómo podemos defender una teoría de las necesidades o de las capacidades básicas sin poner en jaque a la autonomía individual y el valor de la diferencia? Es necesario encontrar un argumento que logre combinar universalidad y diferencia, que defienda los medios de la libertad sin suprimir la libertad misma. Para ello, partamos del siguiente ejemplo: ¿debemos dejar de sancionar la brutal discriminación de las mujeres afganas en el régimen talibán en nombre de la diferencia que suponen las costumbres locales? Podemos pensar que aquí una teoría de las necesidades y capacidades básicas universalmente reconocidas debería denunciar con fuerza y claridad la discriminación de género moralmente arbitraria, porque ninguna razón local debería contravenir la satisfacción de esas necesidades y capacidades básicas iguales que caracterizan lo indiscutiblemente humano. En un caso como éste, la inhibición liberal representa un golpe bajo e innecesario a la igualdad moral de las personas.

El liberalismo kantiano de Rawls y de Dworkin desea hacer a la gente responsable de sus preferencias. Eso significa que, por ejemplo, si algunas mujeres del tercer mundo sufren más desnutrición que los hombres de su comunidad, tienen menos acceso a la educación y son, en general, menos libres y, al mismo tiempo, no muestran deseos de evitar esa discriminación (algunas de ellas la defienden, incluso, a partir de las creencias sociales y religiosas de su entorno), sus respectivas teorías de la justicia no pueden sancionar tal situación, ya que el ideal de persona moral que las fundamenta responsabiliza (culpabiliza) a las personas por sus preferencias. Solamente si entendemos la igualdad en primer lugar como la satisfacción de las necesidades y capacidades básicas que son comunes a la humanidad podemos afrontar con justicia el problema de las preferencias adaptativas. Al fin y al cabo, si la situación de esas mujeres nos afecta moralmente será porque creemos que viola algún aspecto fundamental de la igualdad moral. Ese aspecto fundamental es el que hay que esforzarse por cultivar como cri- 
terio de justicia. Y no creo que se reduzca a un mero compromiso ético con la autonomía formal de las personas y las culturas.

El kantismo en las concepciones rawlsiana y dworkiniana de la persona reduce la moralidad a capacidades autosuficientes, que no necesitan del mundo natural para realizarse, pero es indiferente a la relación entre capacidad de elección y condiciones sociales y materiales de la elección. En cambio, necesitamos una concepción moral de la persona que una a la preocupación kantiana por asegurar la autonomía racional y moral de los individuos la sensibilidad con sus necesidades y vulnerabilidades. La persona moral como sujeto trascendental, alejada de los condicionantes empíricos de la existencia, se debería sustituir por otra que no despreciase lo natural, sino que lo incorporase dentro de las exigencias del desarrollo moral de la persona. La teoría de la justicia debería acercar el reino moral al reino natural.

Al fin y al cabo, si definimos las libertades por los intereses que perseguimos con ellas, es decir, si nos preocupan las libertades por lo que con ellas se defiende (por ejemplo, queremos libertad de pensamiento porque creemos que es moralmente valioso ser dueños de nuestros propios pensamientos; o deseamos libertad de conciencia porque pensamos que es moralmente importante definir por nosotros mismos las finalidades morales que nos afectan), entonces parece un contrasentido fundamentar la igual libertad en una idea abstracta de la persona moralmente libre. Parece más razonable referirse directamente a la igualdad en la satisfacción de esos intereses comunes como la manera más adecuada de interpretar la igualdad en la práctica, es decir, a la hora de aplicar la justicia distributiva. La igualdad moral se debería fundamentar en los intereses comunes de las personas, los más básicos y universales, antes que en una idea abstracta de la libertad como acción incausada (en términos kantianos) o como libertad de elección cuando no hay nada que elegir, o cuando unos tienen infinidad de opciones mientras otros las tienen muy escasas.

Necesitamos una teoría ética de las necesidades humanas básicas que proteja la autonomía de las personas, pero que no descuide ni los medios de la autonomía ni la solidaridad interpersonal. Sin embargo, debemos ser conscientes de las dificultades de una empresa como ésta. Aunque existen algunos intentos de conceptualizar las necesidades con una vocación universalista ${ }^{59}$, en los últimos años han predominado más los ataques a una teoría de ese estilo que su defensa, y esos ataques han provenido de todos los ángulos ideológicos.

Por una parte, la visión historicista del marxismo ha denostado tradicionalmente la idea de necesidades. Aunque es conocida la tesis marxista de distribuir los beneficios sociales con el criterio de las necesidades, no hay que olvidar que ese criterio cobra sentido solamente en una etapa histórica de derrota del capitalismo burgués y de abolición de las clases sociales. El concepto de necesidades no sirve como medida de la justicia distributiva en un mundo social dominado aún por la lucha de clases, en el que las necesidades están socialmente inducidas por los hábitos de consumo y por una superestructura ideológica que viene impuesta por la clase dominante. Las auténticas necesidades humanas no se pueden desvelar hasta haber podido superar los determinismos socioeconómicos que impiden a los individuos descubrirse a sî mismos en su autenticidad y, en consecuencia, poder conocer sus propias necesidades. Agnes Heller ha llevado esta forma de escepticismo hasta sus últimas consecuencias ${ }^{60}$.

Por otra parte, la economía liberal, y también autores de clara inspiración libertarista, como Nozick, Hayek, Green o Flew, han sustituido el concepto de necesidad por las preferencias o la demanda ${ }^{61}$. 
La raíz de esta sustitución va más allá de una simple disparidad de criterios respecto a la interpretación de las necesidades como un factor de acceso al bienestar. Su objetivo es evitar los abusos a los que ha llevado, en general, el lenguaje de las necesidades que insiste en la existencia de necesidades humanas objetivas y universales. Piensan en las experiencias políticas y sociales que en nombre de ese tipo de necesidades (sobre las cuales los individuos no se podían oponer sin incurrir en una especie de autocontradicción en forma de autodesconocimiento, según la versión oficialista) han sometido la libre voluntad de las personas al dictado de las necesidades universales. En parte debido a la desilusión $\mathrm{y}$ al escepticismo provocados por el abuso del concepto de necesidades humanas y en parte también a la dificultad de transformar operacionalmente una idea tan imprecisa y resbaladiza, muchos liberales han afirmado que es moralmente más prudente equiparar las necesidades con las preferencias subjetivas, una tesis que afirma que solamente los individuos, por sí mismos y sin intermediarios sociales, están capacitados para expresar sus apetencias y necesidades.

Pero también otras corrientes del pensamiento actual reniegan de los intentos por definir unas ciertas necesidades humanas universalizables. Para el relativismo cultural, cualquiera interpretación de las necesidades humanas debe circunscribirse a un contexto cerrado de significados para el que nos está vedado el acceso a los provinientes de otro mundo de significados. Una definición universalista de las necesidades representa una intromisión opresora en el derecho de las comunidades y de las minorías a decidir con autonomía sus valores y sus prioridades morales ${ }^{62}$.

Con una argumentación similar se sitúan otros dos grupos de teorías muy productivas en la actualidad: el comunitarismo, del que ya he hablado, y la sociología del conocimiento. El comunitarismo afir- ma que si el lenguaje constituye el modo en que el mundo natural y el social adoptan un significado para los grupos humanos diferentes, que utilizan el lenguaje con usos diferentes, entonces las realidades que abren esos lenguajes distintos deberían tener la misma legitimidad: no existe una verdad o universalidad que trascienda a las experiencias comunitarias sobre los significados de la realidad, no hay una especie de árbitro imparcial y omnicomprensivo entre las diversas interpretaciones de la realidad. Por esa razón, cualquiera definición de una necesidad universal o universalizable es sencillamente un sinsentido, una idea vacía e inútil ${ }^{63}$. Por su parte, la sociología del conocimiento llega a la relatividad de las necesidades por una vía algo diferente. Lo que critican autores como Alfred Schutz, Peter Townsend, G. Smith, Peter Berger y Thomas Luckman es que cualquier concepto abstracto como la idea de necesidades universales suele olvidar el complejo mundo de negociaciones y relaciones sociales entre los individuos que hace falta para moldear las ideas socialmente compartidas. Las necesidades, como otros conceptos demasiado amplios y ambiguos, son construcciones sociales que no se pueden desvincular de las culturas, los grupos humanos y el tiempo que los engendra. Todo lo que podemos hacer, si estamos interesados en descubrir algo parecido a unas necesidades humanas universales, es constatar las similitudes entre las distintas visiones subjetivas de necesidad que encontramos en los diferentes contextos sociales que forman el mapa plural de la humanidad.

Todas esas teorías comparten un profundo escepticismo sobre la idea de necesidades humanas universales. En cambio, sin una visión universalizable de las necesidades y de las capacidades, que abarque aspectos materiales de la existencia, como la educación, la salud o el bienestar económico, la justicia distributiva se encuentra desorientada. Incluso a pesar de las teorías 
relativistas, en ocasiones brillantemente fundamentadas, todavía permanece nuestra intuición ética básica de relacionar justicia y necesidades: la justicia debería proteger a los más necesitados, a los más vulnerables. Si nos conmueve la situación de los que más sufren, esto es porque en el fondo presuponemos una idea común, aunque sea muy amplia y ambigua, de lo que es el sufrimiento y el bienestar humano, y de nuestra responsabilidad moral en ello ${ }^{64}$. Se trata de una responsabilidad que asociamos al ideal universal de justicia y no sólo a una idea local construida para su uso doméstico. El liberalismo kantiano no puede caer en el error de renunciar a la universalidad sin contradecirse en algún sentido importante.

En resumen, he mostrado que la teoría ética de la naturaleza humana que defiende el liberalismo kantiano de Rawls y Dworkin, si bien no admite contenidos morales sustantivos (perfeccionismo en sentido fuerte), está obligado, en cambio, a comprometerse con un sentido universal mínimo de la personalidad moral (perfeccionismo en sentido débil). A pesar de esto, he argumentado que el perfeccionismo débil que representa el liberalismo kantiano resulta insuficiente para fundamentar una concepción de la justicia que tenga en cuenta las necesidades de las personas. También he manifestado que si queremos descargar de responsabilidad a los individuos por las preferencias que éstos desarrollan para adaptarse resignadamente a la desigualdad material, necesitamos una concepción moral de la persona que incluya una visión universal de las necesidades y las capacidades básicas. Entre éstas se debe contar con la capacidad de elección individual de una vida buena, pero siempre como uno más de los requisitos de la igualdad moral, no como su único representante. Delimitar con mayor precisión esa concepción moral de la persona, ese tipo de igualdad moral, es una tarea prioritaria de la filosofía moral y política.
1 Agradezco a Victoria Camps y a Mercè Rius sus lúcidas observaciones a un primer borrador de este texto. También quiero mostrar mi gratitud a Toni Domènech, Albert Calsamiglia, Albert Jovell y Ramón Vargas-Machuca por sus pertinentes y valiosos comentarios a algunas de las ideas que aquí aparecen.

2 Véase el espléndido estudio de Amelia Valcárcel, Del miedo a la igualdad, Barcelona, Crítica, 1993, en el que se analiza con aguda brillantez la historia, el contenido, los problemas y la necesidad moral y política para nuestro tiempo de la idea de igualdad.

3 A excepción de los derechos de los inmigrantes, que en todas las legislaciones nacionales aparecen recortados respecto a los derechos de la ciudadanía en general.

${ }^{4}$ El Estado de bienestar es la fórmula que utilizan las sociedades liberales occidentales para aplicar el principio de igualdad en la economía de las familias. El ideal de una estricta igualdad económica se ha perdido por el camino por muchos motivos, entre los cuales destaca, como razonable, la ineficiencia.
${ }_{5}$ La igualdad de oportunidades es el principio que recoge la necesidad de llevar la igualdad al ámbito de las relaciones sociales. Para un estudio de ese principio y de las dificultades de su definición y aplicación, véase Ángel Puyol, «Los límites de la igualdad de oportunidades», Leviatán, en prensa.

${ }^{6}$ Por ejemplo, Victoria Camps cree que la mujer ha logrado en muchos ámbitos sociales la paridad con los hombres, al menos formalmente, pero «también es indiscutible que la igualdad conseguida es insuficiente. Han cambiado las leyes, pero no cambian las costumbres (...) aún hay obstáculos para una igualdad aceptable, de los cuales creo que debe destacarse que en la vida privada se sigue discriminando a la mujer y se mantiene una división del trabajo muy tradicional, con pocos cambios». V. Camps, El siglo de las mujeres, Madrid, Cátedra, 1998.

${ }^{7}$ Por ejemplo, John Roemer, Gerald A. Cohen, Richard Arneson o Amartya Sen.

${ }^{8}$ Se puede establecer una distinción entre esta visión amplia del utilitarismo, que podríamos llamar bienestarismo, y una visión más precisa que implica 
además que la bondad de las utilidades sea juzgada según su total global, o según la media, o según el producto. Estas versiones más específicas se conocen como utilitarismo de la suma, de la media y del producto respectivamente. En estos casos, el utilitarismo sería un caso particular de bienestarismo.

${ }^{9}$ En otro lugar he mostrado extensamente las dificultades que el utilitarismo muestra para integrar la igualdad entre las exigencias de la justicia distributiva. Véase Ángel Puyol, Justícia i salut, Bellaterra, Servei de Publicacions de la Universitat Autònoma de Barcelona, 1999. Véase también Antoni Domènech, «Ética y economía de bienestar: una panorámica», en O. Guariglia (ed.), Cuestiones morales, Madrid, Trotta, 1996. A esas dificultades se pueden añadir otras que tienen que ver con los problemas del utilitarismo para proteger la integridad de la persona y su carácter moral Para este tipo de críticas, véase B. Williams, «A Critique of Utilitarianism», en J. J. C. Smart y B. Williams, Utilitarianism, For and Against, Cambridge, Cambridge University Press, 1973, pp. 97-104, reimpreso de forma resumida en J. G. Haber (ed.), Doing and Being, London, Macmillan, 1993, pp. 46-50; B. Williams, Moral Luck, Cambridge, Cambridge University Press, 1981, pp. 1-19; J. J. C. Smart, «Utilitarianism and Justice», Journal of Chinese Philosophy, 1978; J. Glover (ed.), Utilitarianism and Its Critics, London, Macmillan, 1990, capítulo 5.

${ }^{10}$ J. Rawls, Teoría de la justicia, México, Fondo de Cultura Económica, p. 44

${ }_{11}$ Ésta es la conocida tesis que sostiene uno de los principales avaladores del utilitarismo clásico. Véase J. Bentham, The Collected Works of Jeremy Bentham, Oxford University Press, 1982 en adelante. En castellano, puede consultarse una excelente antología de textos en Josep M. Colomer (ed.), Bentham, Barcelona, Península, 1991.

${ }_{12}$ Rawls, op. cit., p. 44.

${ }_{13}$ Por ejemplo, Ronald Dworkin defiende los derechos individuales como una especie de triunfos (trumps) de la baraja que los individuos deben proteger contra los posibles abusos del utilitarismo. Los derechos individuales se convierten así en «la promesa que la mayoría hace a las minorías de que la dignidad y la igualdad de éstas serán respetadas». R. Dworkin, Los derechos en serio, Barcelona, Ariel, 1984, p. 303.

14 Véase R. Dworkin, op. cit., p. 341.

${ }^{15}$ H. L. A. Hart, «Between Utility and Rights», en A. Ryan (ed.), The Idea of Freedom, Oxford, Oxford University Press, 1979, p. 95.

${ }^{16}$ Véase E. Guisán, «Las personas en serio (Los derechos humanos y el Bienestar)», Télos, vol. V, núm. 2, junio 1996, pp. 27-46.

${ }_{17}$ Op. cit., p. 43.

18 Véase D. Parfit, Reasons and Persons, Oxford, Clarendom Press, 1987, p. 330.

${ }_{19}$ Para una argumentación en esta línea, véase S. Scheffler, «Ethics, Personal Identity, and Ideals of the Person», Canadian Journal of Philosophy, vol. XII, núm. 2, 1982, pp. 229-246.
${ }^{20}$ Parfit, op. cit., p. 341

21 Op. cit., pp. 335-336.

22 J. Rawls, El liberalismo político, Barcelona, Crítica, 1996, p. 62.

${ }_{23}$ Véase Richard Arneson, «Equality of Opportunity for Welfare», Philosophical Studies, núm. 56, 1989; y «Liberalism, Distributive Subjectivism, and Equal Opportunity for Welfare», Philosophy and Public Affairs, vol. 19, núm. 2, 1990.

${ }_{24}$ Véase Gerald A. Cohen, «On the Currency of Egalitarian Justice», Ethics, núm. 99, 1989; y «Equality of What? On Welfare, Goods and Capabilities», en The Quality of Life, M. Nussbaum y A. Sen (eds.), Oxford, Clarendom Press, 1993.

${ }^{25}$ Véase John Roemer, Theories of distributive jus tice, Cambridge, Mass., Harvard University Press, 1996.

26 Véase sobre todo Amartya K. Sen, Nuevo examen de la desigualdad, Madrid, Alianza, 1995; también Bienestar, justicia y mercado, Barcelona, Paidós, 1997.

27 Recurro a la distinción, creo que ya extendida entre bienestarismo y recursismo para enfatizar la utilización del bienestar o de los recursos, respectivamente, como base de la métrica en una teoría de la justicia distributiva.

${ }^{28}$ Véase Ronald Dworkin, «What Is Equality? Part 1: Equality of Welfare», Philosophy and Public Affairs, vol. 10, núm. 3, 1981; y «What Is Equality? Part 2: Equality of Resources», Philosophy and Public Affairs, vol. 10, núm. 4, 1981.

${ }^{29}$ J. Rawls, «Social unity and primary goods», en A. Sen y B. Williams (eds.), Utilitarianism and Beyond, Cambridge, Cambridge University Press, 1982, p. 180 (traducción en J. Rawls, Justicia como equidad, Madrid, Tecnos, 1986, p. 207). El texto de Arrow se encuentra en K. Arrow, «Extended Sympathy and the Possibility of Social Choice», American Economic Review, Supplementary Issue of the Proceedings, 1977, pp. 222-223.

30 Ésa es una de las razones por las cuales Arrow renuncia al utilitarismo clásico a favor del utilitarismo ordinalista (sustituyendo así la maximización de la suma del bienestar por la optimalidad paretiana como criterio de la distribución justa), pero no cree necesario rechazar el bienestarismo como base de la métrica distributiva.

31 Además de sus dos obras citadas, hay que mencionar la recopilación de casi todos sus artículos a lo largo de más de treinta años, reunida por Samuel Freeman en J. Rawls, Collected Papers, Cambridge, Mass., Harvard University Press, 1999. También de aparición muy reciente son sus últimos textos sobre la internacionalidad de la teoría de la justicia, en J. Rawls, The Law of Peoples, Cambridge, Mass., Harvard University Press, 1999.

32 Para una exploración sobre la peculiar concepción rawlsiana del consenso entrecruzado, véase El liberalismo político, ed. cit., segunda parte.

${ }^{33}$ En su teoría de la justicia, Rawls expone que las personas son razonables si son capaces de cooperar con los demás y de adquirir un sentido de la justicia que permita la convivencia. La razonabilidad, junto 
a la racionalidad - la capacidad de concebir y de perseguir los intereses propios del modo más eficaz- son dos características fundamentales de la persona moral rawlsiana.

${ }^{34}$ Véase I. Kant, Fundamentación de la metafísica de las costumbres, Madrid, Espasa-Calpe, 1981, p. 97.

${ }^{35}$ Véase J. Rawls, A Theory of Justice, Oxford, Oxford University Press, 1973, p. 253. En este caso, la traducción castellana en la edición de Fondo de Cultura Económica es deficiente.

${ }_{36}$ Véase J. Rawls, Una teoría de la justicia, ed. cit., p. 164 .

${ }^{37}$ Una primera versión de este tipo de crítica fue presentada en la IX Semana de Ética y Filosofía Política celebrada en Tenerife a finales de marzo de 1998. Véase Ángel Puyol, «Liberalismo igualitarista, persona moral y universalismo», Laguna, núm. extraordinario, 1999, pp. 225-234.

${ }^{38}$ Véase, por ejemplo, Will Kymlicka, Liberalism, Community and Culture, Oxford, Clarendom Press, 1991, pp. 21-43; véase también William Galston, Liberal Purposes, Cambridge, Cambridge University Press, 1991, y R. Grundmann y C. Mantziaris, Habermas, Rawls, and the Paradox of Impartiality, Firenze, EUI Working Paper, núm. 90-91, 1990, pp. 1-35. Para una exposición del conflicto entre lo correcto y lo bueno, véase R. B. Douglass, G. M. Mara y H. S. Richardson (eds.), Liberalism and the Good, New York, Routledge, 1990.

${ }^{39}$ Véase Michael Sandel, Liberalism and the Limits of Justice, Cambridge, Cambridge University Press, 1982, p. 180.

${ }^{40}$ Véase Alasdair MacIntyre, «How Moral Agents Have Become Ghosts?», Synthese, 53, 1982 , pp. 295-312.

${ }^{41}$ Véase Ch. Taylor, «The Diversity of Goods», Philosophical Papers, vol. II, 1985, p. 233.

42 B. Williams, Moral Luck, Cambridge, Cambridge University Press, 1981, p. 19. Para un estudio global del ataque comunitarista al liberalismo rawlsiano, véase S. Mulhall y A. Swift, El individuo frente a la comunidad, Madrid, Temas de Hoy, 1996.

${ }^{43}$ Véase Rawls, El liberalismo político, ed. cit., pp. 57-58.

${ }^{44}$ Véase Ronald Dworkin, Ética privada e igualitarismo político, Barcelona, Paidós, 1993.

45 «Los liberales éticos son gente real: se trata de ustedes y de mí, y de otros centenares que puedan bastar para representar todas las variantes principales de las convicciones éticas concretas en las comunidades políticas que nos son familiares», Dworkin, op. cit., p. 163.

${ }^{46}$ Op. cit., pp. $174-175$

${ }^{47}$ La disociación entre los ámbitos público y privado en la teoría política liberal es también el centro de las críticas que el feminismo liberal dirige al liberalismo político de Rawls, alrededor de la consigna «lo personal es también político». Para una presentación de estas ideas, véase C. Pateman, "Críticas feministas a la dicotomía público-privado», en C. Castells (ed.), Perspec- tivas feministas en teoría política, Barcelona, Paidós, 1996, pp. 31-53.

48 Para un amplio estudio acerca de la formación de las preferencias adaptativas, véase Jon Elster, Uvas amargas, Barcelona, Península, 1988.

${ }^{49}$ Sobre las contradicciones internas de la igualdad liberal, véase Ángel Puyol, «La inestabilidad del igualitarismo político», en Reyes Mate (ed.), Pensar la igualdad y la diferencia, Madrid, Visor, pp. 47-62.

${ }_{50}$ Para este tipo de crítica, véase H. Hart, «Rawls on Liberty and Its Priority», y N. Daniels, «Equal Liberty and Unequal Worth of Liberty», ambos en N. Daniels (ed.), Reading Rawls, Stanford, Stanford University Press, 1975.

${ }_{51}$ Recordemos que en sentido estricto el principio de la diferencia permite inmensos beneficios económicos para unos cuantos a cambio de ínfimas ganancias para los más pobres

${ }_{52}$ Véase J. Rawls, Sobre las libertades, Barcelona, Paidós, 1990 (original de 1982), p. 75.

53 Para un amplio estudio sobre el perfeccionismo, véase la espléndida obra de Thomas Hurka, Perfectionism, Oxford, Oxford University Press, 1993. También se puede consultar la obra de V. Haksar, Equality, Liberty, and Perfectionism, Oxford, Oxford University Press, 1979.

${ }_{54}$ Robert Nozick, Anarquía, estado y utopía, México, Fondo de Cultura Económica, 1990, pp. 44-45.

${ }_{55}$ Véase R. Nozick, «Distributive justice», Philosophy and Public Affairs, vol. 3, 1973

${ }_{56}$ Nussbaum llama esencialismo a lo que yo me estoy refiriendo como perfeccionismo. Con esa terminología, el esencialismo metafísico correspondería al perfeccionismo en sentido fuerte, y el esencialismo internalista equivaldría, por su parte, al perfeccionismo en sentido débil. Véase Marta Nussbaum, «Aristotelian Social Democracy», en R. B. Douglas et al. (eds.), Liberalism and the Good, ed. cit., pp. 203-252; y también «Human Functioning and Social Justice», Political Theory, vol. 20, núm. 2, 1992, pp. 202-246.

57 Véase M. Nussbaum, «Human Functioning and Social Justice», op. cit., p. 215.

${ }^{58}$ Las réplicas de Sen a la lista de capacidades básicas que ha elaborado Nussbaum se pueden encontrar en A. Sen, «Capability and Well-Being», A. Sen y M. Nussbaum (eds.), The Quality of Life, ed. cit., pp. 30-53.

${ }^{59}$ Véase, por ejemplo, L. Doyal y I. Gogh, Teoría de las necesidades humanas, Barcelona, Crítica, 1994

${ }^{60}$ Véase A. Heller, Teoría de las necesidades en Marx, Barcelona, Ed. 62, 1986.

${ }^{61}$ Véase R. Nozick, Anarquía, estado y utopía, ed cit.; F. Hayek, Camino de servidumbre, Madrid, Alianza, 1990; A. Flew, «Wants or Needs, Choices or Commands», en R. Fitzgerald (ed.), Human needs and politics, Sydney, Pergamon, 1977, y D. Green, The New Right, Brighton, Wheatsheaff, 1987.

${ }_{62}$ Véase, por ejemplo, G. Rist, «Basic questions about basic human needs», en K. Lederer (ed.), Human needs, Cambridge, Mass., Oelgeschlager, 1980. 
${ }^{63}$ Véase Ch. Taylor, Philosophy and the Human Sciences: Philosophical Papers, ii, ed. cit.

${ }^{64}$ Incluso en teoría económica normativa se suele presuponer una idea abstracta del bienestar, que no se infiere directamente de las preferencias personales, suficientemente general como para que no se identifique con una idea particular o personal del bien, pero desde donde poder argumentar moralmente y discutir aspectos de las políticas sociales. Esta consideración se puede encontrar en Thomas Scanlon, «The Moral Basis of Interpersonal Comparisons», en J. Elster y J. Roemer (eds.), Interpersonal Comparisons of Well-Being, Cambridge University Press, Cambridge, 1991. 